\title{
Morte Repentina de Genitores e Luto Infantil: Uma Revisão da Literatura em Periódicos Científicos Brasileiros
}

\author{
Márcia Camaratta Anton", \& Eveline Favero \\ Universidade Federal do Rio Grande do Sul, Porto Alegre, Brasil
}

\begin{abstract}
RESUMO
Este artigo buscou revisar a literatura sobre luto infantil decorrente de morte repentina de genitores, publicada em periódicos científicos brasileiros, nos últimos quinze anos. Foram abordadas as consequências emocionais deste evento para na vida da criança e as diferentes abordagens psicoterápicas utilizadas. A busca nas bases de dados Index Psi, PsycINFO, Web of Science, Scopus, Medline, SciELO, Bireme e BVS-Psi resultou em 11 publicações em revistas brasileiras, sendo duas de autoria estrangeira. A análise dos artigos mostrou a relevância da comunicação aberta com a criança e a criação de um espaço de escuta e expressão dos sentimentos. Os resultados apontaram a relevância do atendimento psicoterapêutico à criança e aos seus cuidadores a fim de auxiliar a ambos no processo de elaboração da perda.
\end{abstract}

Palavras-chave: luto; criança; morte repentina.

\section{ABSTRACT \\ Sudden Death of Parents and Child Mourning: A Literature Review From Brazilian Journals}

The present study reviewed the publications in Brazilian journals in the past fifteen years concerning child mourning due to the sudden death of parents. The emotional consequences of this event in the child's life and the different psychotherapeutic approaches to the problem are discussed. The database search on Index Psi, PsycINFO, Web of Science, Scopus, Medline, SciELO, Bireme e BVS-Psi resulted in 11 publications in Brazilian journals; two articles were by non-Brazilian authors. Analysis of the articles has shown the importance of open communication with the child, and of listening and expressing feelings. The results stressed the relevance of psychotherapy in helping the child and his/her caretakers to deal with the process of loss.

Keywords: mourning; child; sudden death.

Várias circunstâncias podem separar os filhos pequenos de seus pais por algum tempo ou definitivamente. Neste último caso, a morte de genitores pode afetar o desenvolvimento infantil tanto a curto quanto a longo prazo (Bowlby, 1970/2006), já que o rompimento de um vínculo por morte exige uma reorganização emocional por parte da criança e da família (Franco \& Mazorra, 2007). A separação por morte configura-se em potencial estressor para a criança, podendo colocar em risco a sua segurança e sobrevivência emocional (Franco \& Mazorra, 2007), quando não também a material. Soma-se a isto o fato desta estar inserida em um grupo familiar que, pelo impacto do evento, tende a também se encontrar fragilizado (Cole \& Cole, 2003). Essas questões tornam o luto infantil um tema complexo que merece ser aprofundado. O conhecimento sobre o assunto é essencial para se entender as implicações da morte de genitores para a criança, bem como para orientar famílias e instituições na busca por terapias e fontes de apoio efetivas para as crianças adversamente afetadas por tais perdas. Assim sendo, o objetivo do presente artigo é de revisar as publicações em periódicos científicos brasileiros a respeito do luto infantil decorrente de morte repentina de um ou ambos os genitores, publicados nos últimos quinze anos. Além disso, busca investigar

\footnotetext{
Endereço para correspondência: Márcia Camaratta Anton, Serviço de Psicologia do HCPA, Rua Ramiro Barcelos, 2.350, Largo Eduardo Faraco, Porto Alegre, RS, CEP 90035-903. E-mail: manton@hcpa.ufrgs.br ou marciacamaratta@gmail.com.
} 
quais as possíveis consequências emocionais deste evento na vida da criança e as diferentes abordagens psicoterápicas utilizadas.

No rol de tipos de perdas por morte que podem acometer indivíduos ou grupos populacionais encontra-se o que denominamos neste artigo de "morte repentina", ou seja, aquela que ocorre de forma súbita e inesperada. Inclui-se aqui: acidentes diversos, homicídios, suicídios, latrocínio, infarto fulminante, AVC, desastres naturais ou humanamente induzidos, dentre outros. Entende-se que a morte repentina de um genitor diferencia-se em seu impacto sobre a vida e a estrutura emocional da criança, em relação às mortes que possam ser esperadas ou até mesmo compreendidas como resultado do ciclo vital, tais como morte de avós ou pais já idosos, quando o filho encontra-se na idade adulta. Isto porque estas perdas abruptas, ocorridas de forma acidental ou intencional, quase sempre têm um caráter traumático para os familiares sobreviventes e mais ainda para as crianças (Kinijnik \& Zavaschi, 1994).

O termo trauma, de origem grega, significa lesão (Ferreira, 1986). Do ponto de vista psicanalítico, trauma refere-se a um choque violento capaz de romper a barreira protetora do ego, podendo acarretar perturbações duradouras sobre a organização psíquica do indivíduo (Freud, 1916/1969). Assim, trauma provém de um acontecimento na vida do indivíduo, que se define pela sua intensidade e pela incapacidade do sujeito de responder de forma adequada, provocando transtornos e efeitos patogênicos na organização psíquica do indivíduo (Laplanche \& Pontalis, 1986). Caracteriza-se, portanto, como um período de desequilíbrio psicológico, resultante de um evento ou situação danosa, a qual o indivíduo não consegue resolver utilizando suas estratégias defensivas usuais, geralmente levando a um estado de crise (Franco, 2005).

As perdas repentinas, violentas e prematuras podem ser consideradas dentre as mais difíceis de serem elaboradas (Domingos \& Maluf, 2003; Franco, 2005). Torres (1996) entende que a maior crise com a qual uma criança pode se deparar é a morte repentina de um ou de ambos os pais, a qual afeta o sentimento de onipotência infantil, ao mostrar para a criança que seus pais não são seres superpoderosos, como imaginava. Da mesma forma, pode surgir culpa, por impulsos agressivos, que a criança acredita terem tornado-se realidade, através da morte. Além disso, nas situações de morte repentina, diferentemente do que ocorre na morte esperada, a criança não tem a chance de fazer um luto antecipatório, de maneira a preparar-se psicologicamente para tal evento. Este termo, cunhado por Fonseca (2004), refere-se a um fenômeno adaptativo, que pode ocorrer em situações de morte esperada, nas quais é possível, tanto para o paciente como para os familiares, prepararem-se cognitiva e emocionalmente para a perda. Nestes casos, o tempo que a família ainda dispõe com o membro doente é fundamental para que possam resolver alguns conflitos e questões objetivas, assim como para que as emoções sejam expressas, favorecendo a despedida.

A morte repentina de um genitor gera, ainda, uma série de mudanças que ultrapassam o desaparecimento da pessoa. Com a morte de um dos genitores a criança perde também os pais da forma como eram anteriormente, já que o sobrevivente também se modifica em seus aspectos emocionais, comportamentais e nos papéis que necessitam ser readaptados (Raimbault, 1979). Assim, segundo o autor, a criança é submetida a uma tarefa ainda mais complexa que a do adulto, pois a perda a priva também de uma base segura e de identificação. Seu referencial em relação àqueles que sobreviveram é alterado, a medida que estes também encontram-se enlutados e, portanto, modificados em sua forma de se expressar e agir. Desta forma, com a morte de um genitor, a criança perde também o mundo que ela conhecia, tornando-se difícil lidar com toda a gama de sentimentos que a invadem com o desmoronamento da família (Franco \& Mazorra, 2007).

Neste sentido, Bowlby (1970/2006) afirma que a perda de uma figura de vínculo é percebida pela criança como desamparo. Dentre os efeitos mais intensos e perturbadores provocados pela perda do genitor encontram-se o medo de ser abandonado, a saudade da figura perdida e a raiva por não poder reencontrá-la. Assim, quando alguém tão significativo morre, o sujeito é remetido a sensações básicas experimentadas quando o bebê é afastado da mãe, pairando uma ameaça sobre a própria sobrevivência do enlutado (Nascimento \& Coelho, 2006). Tudo isso pode aumentar a ansiedade de separação da criança, que se encontra em processo de luto (Bowlby, 1970/2006).

Para Bowlby (1989), "enquanto a ansiedade de separação é a resposta usual a uma ameaça ou a algum outro risco de perda, o luto é a resposta usual a uma perda, depois dela ter ocorrido" (p. 42). Configura-se 
em uma constelação de reações psíquicas, conscientes e inconscientes diante de uma perda significativa. É a resposta a quebra de um vínculo afetivo, o qual tem um valor de sobrevivência (Bowlby, 1993). Assim, o luto adquire a função de proporcionar a reconstrução de recursos e viabilizar um processo de adaptação às mudanças ocorridas (Franco, 2005; Nascimento \& Coelho, 2006).

Bowlby (1970/1997) descreve quatro fases do luto, as quais comumente seguem um padrão básico, ainda que se diferenciem em relação à intensidade e duração para cada sujeito. A primeira fase - de torpor ou aturdimento - geralmente tem a duração de algumas horas ou semanas, podendo vir acompanhada de manifestações de desespero ou raiva. A segunda, denominada saudade e busca da figura perdida, pode durar meses ou anos, e caracteriza-se pelo impulso de buscar e recuperar o ente querido, sendo que a raiva pode mostrar-se presente, quando o indivíduo percebe realmente o fato a perda. Na terceira fase - desorganização e desespero - é freqüente o choro, a raiva, acusações envolvendo pessoas próximas e uma profunda tristeza, em virtude da constatação do caráter definitivo da perda. Nesta fase, podem surgir sentimentos mais depressivos, com sensação de que nada mais tem valor. Na quarta fase - organização - ocorre a aceitação da perda e a constatação de que uma nova vida precisa ser iniciada. Segundo o autor, a saudade, a necessidade do outro e a tristeza podem retornar em qualquer fase, já que o processo de luto nunca está totalmente concluído.

Em situações de perda repentina, segundo Bowlby (1970/2006), a fase de protesto e busca da figura perdida (Fase 2) tende a ser vivida com mais intensidade, sendo que o indivíduo enlutado se empenha, na realidade ou em pensamento, em recuperar a pessoa perdida, recriminando-a pelo seu desaparecimento. Nesta fase, surgem sentimentos ambivalentes, incluindo raiva, esperança e desespero. A raiva em relação ao falecido, segundo o autor, é parte integrante da reação de pesar, podendo, em contrapartida, mobilizar culpa, por ser percebida como um sentimento indigno e degradante. No entanto, para que haja a elaboração da perda, é necessário que o indivíduo possa expressar e lidar com os mais diferentes sentimentos suscitados pela morte. Neste sentido, Bowlby (1970/2006) afirma que a incapacidade para expressar abertamente esses impulsos pode levar ao desenvolvimento de um luto patológico, com dificuldade de elaboração da perda.
Além desses aspectos, vários outros fatores influenciam o luto das crianças, dentre eles o conhecimento que têm sobre a perda, os padrões de relacionamento familiar anteriores e subseqüentes à morte, e, especialmente, a oportunidade que lhe é dada para compartilhar seus sentimentos e emoções (Bowlby, 1973/1993). Em relação ao contar ou não para a criança sobre a morte do genitor, Gauderer (1987) acredita que sonegar informações às crianças tem por base o senso comum, segundo o qual elas não teriam capacidade de sentir e compreender a perda e de que expô-las a tal informação poderia traumatizá-las. Aberastury (1984) e Bowlby (1973/1993) consideram essa dificuldade em lidar com a morte e com o sofrimento infantil como da esfera dos adultos. Segundo os autores, ao contrário do que se costuma pensar, a criança assimila a perda e se mobiliza com esta realidade, de modo que conversar com a criança, falando a verdade, é importante para que possa realizar o processo de luto de uma forma saudável.

O diálogo com a criança sobre a morte, para Torres (1996), deve levar em conta sua capacidade compreensiva, de acordo com o período de desenvolvimento. Segundo a autora, dependendo da fase de seu desenvolvimento, a criança não compreende da mesma forma que o adulto os componentes fundamentais para a definição da morte, a saber, a irreversibilidade, universalidade e não funcionalidade da morte. No entanto, isso não significa que não tenha nenhuma compreensão sobre o evento.

Estudos mostram que crianças com menos de cinco anos vêem a morte como algo reversível, muito parecido com o sono e a separação, não tendo noção de causa e efeito (Gauderer, 1987). Nestes casos, seria importante deixar claro para a criança que a pessoa morreu, dando exemplos concretos e palpáveis, de um fato real que elas tenham vivenciado (morte de um animal, por exemplo). Segundo o autor, enganar a criança pode gerar raiva e frustração em relação ao adulto que lhe mentiu, abalando a relação de confiança. Entre os cinco e os sete anos, além de um exemplo concreto, a criança já pode receber explicações mais minuciosas sobre o fato, já que sua capacidade de julgar causa e efeito está desenvolvida. A partir dos oito anos, a criança, de modo geral, já vê a morte como irreversível, mas não como natural, podendo entendê-la como uma punição. Neste caso, cabe ao adulto corrigir as distorções da criança, de modo a amenizar a culpa e o desenvolvimento de sintomas psicos- 
somáticos. Aos nove anos, a morte passa a ser entendida como universal e não necessariamente induzida por alguém, de forma que a criança já se mostra capaz de participar das conversas como os adultos (Gauderer, 1987). Assim, independentemente da idade da criança é importante informá-la sobre o evento, adaptando o linguajar e a complexidade da explicação ao seu nível de compreensão.

\section{MÉTODO}

Para fins deste trabalho foi realizada uma revisão bibliográfica dos artigos publicados em revistas científicas brasileiras, nos últimos 15 anos, cujo resumo encontrava-se disponível nas seguintes bases de dados: Index Psi, PsycINFO, Web of Science, Scopus, Medline, SciELO, Bireme e BVS-Psi. Devido ao reduzido número de artigos encontrados, procurou-se ampliar a busca, utilizando-se diversos descritores de forma isolada e combinadamente, em português e inglês: luto, perda traumática, perda repentina, trauma, transtorno de estresse pós-traumático (TEPT), morte, morte súbita, morte repentina, morte traumática, acidente, desastres, psicoterapia infantil, criança, pais, infância, genitores. Nos resultados foram desconsiderados os bancos de teses e publicações, assim como os artigos publicados em periódicos internacionais.

Foram selecionados para a análise aqueles artigos que abordavam perda por morte repentina de genitor na infância. Foram excluídos aqueles que tratavam de perda não ocasionada por morte e perdas por morte esperada, como as que são antecedidas por adoecimento. Após leitura dos artigos, os dados foram classificados em categorias temáticas descritas a seguir.

\section{RESULTADOS E DISCUSSÃO}

A busca às bases de dados resultou em 11 publicações em revistas brasileiras, sendo dois trabalhos de autoria estrangeira. A Tabela 1 apresenta a temática dos artigos, tipo de estudo e referencial teórico adotado.

\section{Tabela 1}

Abordagem dos Artigos Sobre Luto Infantil por Perda Repentina de Genitores Publicados em Periódicos Brasileiros

\begin{tabular}{|c|c|c|c|}
\hline Temática & Autores & Tipo de Estudo & Referencial Adotado \\
\hline $\begin{array}{l}\text { Luto violento: morte por latrocínio e } \\
\text { homicídio }\end{array}$ & Affonso (2003) & Relato de experiência & $\begin{array}{l}\text { Psicoterapia breve de orientação } \\
\text { familiar, referencial da saúde }\end{array}$ \\
\hline $\begin{array}{l}\text { Morte no episódio de 11/11/01 em } \\
\text { Nova lorque, perda ambígua }\end{array}$ & Boss (2005) & Relato de experiência & $\begin{array}{l}\text { Terapia Familiar, perspectiva } \\
\text { sociológica e psicológica }\end{array}$ \\
\hline $\begin{array}{l}\text { Perda por morte violenta (homicídio, } \\
\text { suicídio) e aids }\end{array}$ & $\begin{array}{l}\text { Domingos \& Maluf } \\
(2003)\end{array}$ & Qualitativo & Psicanalítico \\
\hline Contratransferência e trauma psíquico & $\begin{array}{l}\text { Eizirik e cols. } \\
(2006)\end{array}$ & $\begin{array}{l}\text { Revisão de literatura, Discussão } \\
\text { teórica e técnica }\end{array}$ & Psicanalítico \\
\hline $\begin{array}{l}\text { Impacto do exercício da psicoterapia } \\
\text { nos psicoterapeutas }\end{array}$ & $\begin{array}{l}\text { Fernandes \& Maia } \\
(2008)\end{array}$ & Revisão de literatura & Perspectiva narrativa \\
\hline Morte de familiares em desastre aéreo & Franco (2005) & Discussão teórica e técnica & Psicanalítico \\
\hline $\begin{array}{l}\text { Perda de um ou ambos os genitores: } \\
\text { assassinato, acidente, infarto, aids }\end{array}$ & $\begin{array}{l}\text { Franco \& Mazorra } \\
(2007)\end{array}$ & $\begin{array}{l}\text { Qualitativo (estudo de casos } \\
\text { clínicos }\end{array}$ & Psicanalítico \\
\hline $\begin{array}{l}\text { Perda parental na infância associada } \\
\text { à psicopatologia na vida adulta }\end{array}$ & $\begin{array}{l}\text { Knijinik \& Zavaschi } \\
\text { (1994) }\end{array}$ & $\begin{array}{l}\text { Revisão de literatura e estudo de } \\
\text { caso clínico }\end{array}$ & Psicanalítico \\
\hline Morte de genitor na infância & Mazorra (2001) & Não foi possível acessar o artigo & Psicanalítico \\
\hline A criança diante da morte & Torres (1996) & $\begin{array}{l}\text { Revisão de literatura, Discussão } \\
\text { teórica e técnica }\end{array}$ & Psicologia do desenvolvimento \\
\hline $\begin{array}{l}\text { Perda traumática na infância e } \\
\text { depressão na vida adulta }\end{array}$ & $\begin{array}{l}\text { Zavaschi e cols. } \\
(2002)\end{array}$ & Revisão de Literatura & Psicanalítico \\
\hline
\end{tabular}

Como pode ser visto, os resultados da busca corroboram os achados de Franco e Mazorra (2007) e Zavaschi e cols. (2002) que indicaram em pesquisas anteriores a escassez de publicações nacionais sobre luto na infância. Pode-se inferir que um dos motivos está relacionado ao fato de a maioria dos profissionais 
que trabalha com perdas na infância estar vinculada à clínica e nem sempre à academia, de onde provém a maior parte das publicações. Além disso, este é um tema difícil de pesquisar, já que envolve questões éticas importantes, na medida em que existe um intenso sofrimento emocional envolvido. Assim, pesquisar luto infantil implica em mobilizar ainda mais estas crianças e suas famílias, de forma que um suporte emocional adequado, envolvendo psicoterapia, deve estar presente.

Os resultados dos artigos serão descritos e discutidos a partir de duas categorias de análise. A primeira categoria, denominada Luto infantil e o impacto da perda de genitores na infância aborda fatores facilitadores ou entraves no processo de luto, bem como considerações relativas à perda repentina na infância. A segunda categoria, denominada Psicoterapia em situação de luto infantil por perda repentina de genitores, enfoca orientações dos profissionais que lidam com crianças enlutadas e suas famílias.

\section{Luto infantil e o impacto da perda de genitores na infância}

Os artigos revisados corroboram considerações destacadas por autores clássicos como Bowlby (1970/2006) e Aberastury (1984), mostrando que vários fatores influenciam o luto das crianças, facilitando-o ou dificultando-o. Dentre estes fatores, são destacados o conhecimento que a criança tem sobre a perda, os padrões de relacionamento familiar anteriores, as mudanças subseqüentes à morte, e, especialmente, a oportunidade que lhes é dada para compartilhar seus sentimentos e emoções (Domingos \& Maluf, 2003; Franco \& Mazorra, 2007; Torres, 1996).

Ao tratar dificuldades de elaboração do luto, Knijnik e Zavaschi (1994) apontaram para a valorização de fatores anteriores, concomitantes e posteriores ao trauma, que de forma cumulativa parecem aumentar o risco de um mau prognóstico. Dentre eles, encontram-se, por exemplo, um impacto muito intenso da perda no familiar com quem a criança ficou aos cuidados, mais de uma perda na família, mudança de escola e cidade, a falta de comunicação aberta sobre o tema e a impossibilidade de expressar seus sentimentos. Além disso, são considerados grupos de risco, pelos autores, aquelas crianças que provém de famílias disfuncionais, com discórdia marital, que experimentam relação conflituosa ou história de separação prolongada de um dos pais. Outros autores (Domingos
\& Maluf, 2003; Boss, 2005; Franco, 2005; Zavaschi e cols., 2002) referiram-se ainda à existência de segredos relativos à morte ou a sua causa, a falta de rituais de despedida, ausência de suporte e outras perdas concomitantes na vida da criança, sejam elas secundárias (simbólicas) ou reais. Neste sentido, Zavaschi e cols. (2002) afirmam que a não participação nos rituais de morte do pai ou mãe por parte da criança acarreta maiores índices de depressão na vida adulta e a vivência de sentimentos de culpa. Este achado enfatiza a importância de apoio e permissão para que a criança possa participar e falar abertamente sobre sua dor com os seus familiares.

Quanto à relação entre as causas da morte e o luto, Domingos e Maluf (2003) desenvolveram uma pesquisa com o objetivo de examinar as experiências de perda e de luto vivenciadas por um grupo de escolares. Participaram do estudo 25 adolescentes brasileiros, residentes na cidade de São Paulo, com idades entre 13 e 18 anos, que haviam perdido um ente querido na infância ou na própria adolescência. A coleta de dados se deu por meio de entrevistas clínicas, semidirigidas, que abordaram temas como: circunstâncias da morte, relacionamento com o falecido, reações à perda, impacto nas atividades e no relacionamento com outros e o suporte escolar e familiar. A análise de conteúdo qualitativa revelou que a perda de genitores por morte na infância e adolescência causou uma intensa desorientação, sentimento de desespero, desamparo e vulnerabilidade, além de sentimento de frustração pela privação de gratificações fornecidas anteriormente pelo falecido no desempenho de diferentes papéis.

Estes achados colocam em relevo o impacto das perdas secundárias, tais como mudança de residência, falta ou alteração da figura de identificação e apoio, mudanças de moradia, escola ou vínculos de modo geral, dando ênfase para aquelas de natureza psicossocial. Os resultados indicaram também que situações de homicídio e suicídio, assim como mortes envolvendo consumo de drogas ou aids, tendem a mobilizar fortes conteúdos emocionais, cuja expressão e elaboração tornam-se mais difíceis por serem fatos crivados de juízos de valor e objeto de estigmas socialmente construídos. Além desses aspectos, os resultados apontaram que o ocultamento de informações impediu que os entrevistados participassem plenamente dos acontecimentos relacionados à perda, dificultando o processo de reconhecimento da realidade e a socialização 
do pesar. O desencontro ou falta de informações, a dificuldade da família em compartilhar os acontecimentos da perda, o receio dos sobreviventes em se expor, ou a dificuldade de explicar para si mesmos e para os outros os detalhes sobre a morte foram aspectos que contribuíram para deixar os sobreviventes sem o devido suporte social, aumentando a dificuldade para elaboração da perda. Alguns dos adolescentes entrevistados consideraram que, tendo sofrido a perda na infância, apenas tardiamente, na adolescência, puderam dar-se conta do quanto estas perdas foram importantes. Nas situações de perdas repentinas, as reações das crianças e adolescentes foram de tristeza, ressentimento, autocomiseração, desespero, resignação, desorientação, culpa por não ter podido evitar a morte, raiva e revolta pelo ocorrido.

Nas famílias dos estudantes pesquisados por Domingos e Maluf, as mudanças ocasionadas pela perda e o próprio processo de luto atingiram o equilíbrio familiar, desencadeando ou acirrando conflitos intrafamiliares, muitas vezes associados à necessidade de expressão de fortes emoções que tomaram a forma de revoltas e acusações. Os autores postularam que estas vivências parecem estar relacionadas a situações como padrão afetivo familiar pouco responsivo às necessidades dos jovens enlutados e ao fato dos parentes também estarem passando pela situação de luto e necessitando de apoio. Este contexto familiar de luto, segundo os autores, tornou as famílias fonte de suporte ineficaz para os jovens enlutados. Da mesma forma, a comunidade escolar, segundo os entrevistados, mostrou-se pouco efetiva e às vezes ausente como fonte de suporte às necessidades emocionais decorrentes da perda. Assim, os autores evidenciaram a existência de um conjunto dinâmico de fatores de ordem individual, familiar e escolar por trás das dificuldades dos adolescentes pesquisados em lidar com a perda e conseguir suporte.

Franco e Mazorra (2007), por sua vez, realizaram um estudo de casos clínicos com cinco crianças, de três a oito anos de idade, para as quais foi procurado atendimento psicológico no laboratório de estudos e intervenções sobre luto de uma clínica-escola. O objetivo da pesquisa foi investigar as fantasias da criança enlutada pela morte de um ou ambos os genitores e como estas se relacionam com o processo de elaboração do luto. Para tanto, utilizaram entrevistas clínicas (iniciais e de devolução) com o genitor sobrevivente ou cuidador, entrevista familiar, entrevista lúdica e procedimento desenho-estória. Os resultados apontaram predominância do sentimento de desamparo na mobilização das fantasias das crianças, assim como ocorrência de sentimento de profunda ameaça à sobrevivência física e emocional. Estes aspectos foram agravados pela perda da situação familiar anterior à morte, pela necessidade de reorganização familiar e pelo enlutamento do genitor ou familiares sobreviventes. As autoras concluíram que ao perder um genitor a criança passaria por uma dupla perda, a daquele que morreu e a daquele que ficou e que se encontra fragilizado pela situação, o que acarreta uma sensação de maior desamparo.

O mesmo estudo demonstrou a ocorrência de um frequente sentimento de abandono, em função da grande idealização das figuras parentais e da onipotência infantil, o que torna difícil para a criança compreender que os pais podem sofrer algo, independentemente da sua vontade. Fantasias de ser responsável pela morte se fizeram presentes em todas as crianças, em maior ou menor grau. As autoras constataram, ainda, que a agressividade reprimida em relação ao objeto perdido, pode ser um entrave para a elaboração do luto, sendo que a dificuldade da criança em expressar sentimentos hostis encontra-se relacionada a pouca continência familiar. Desta forma, ressaltaram que se torna importante que alguém possa exercer a função de continência para os sentimentos de raiva da criança, ajudando-a a lidar com a ambivalência emocional e a culpa provocada pela morte do genitor (Franco \& Mazorra, 2007).

Boss (2005) verificou que, em culturas onde há a negação da morte e resistência à perda, as pessoas conseguem dar adeus com mais facilidade quando há evidências do fato, ou seja, quando há a presença de um corpo e um ritual de despedida. Para a autora, os rituais e símbolos seriam o âmago da vida em família e no caso da morte seriam especialmente úteis para reconstruir as interações.

No caso de perda ambígua, ou seja, morte suposta devido à ausência do corpo que comprove sua ocorrência, duas consequências são características de acordo com Boss (2005): a dificuldade de elaboração e a paralisação da vida. Nestas situações, segundo a autora, a resolução da perda raramente é efetiva, podendo haver sentimentos de desesperança que levam à depressão, e de passividade e ambivalência que geram culpa e imobilização. Além disso, tais situações irresolúveis tendem a bloquear a cognição, criar percep- 
ções confusas, bloquear o manejo de enfrentamento do estresse e congelar o processo de luto, criando sintomas similares ao da traumatização e luto complicado. O segredo a respeito da morte seria um agravante, pois ajudaria a manter a negação da perda e dificultaria sua elaboração de modo que falar abertamente com a criança sobre o assunto poderia configurar-se numa atitude saudável.

Em se tratando de perdas coletivas, como as que ocorrem em situações de desastres - terremotos, inundações, furacões, atentados, acidentes aéreos, entre outros - a existência de um sistema de apoio dentro e fora da comunidade envolvida, seria especialmente útil (Franco, 2005). Para Affonso (2003), as crianças que perdem seus pais necessitam de continência social, já que a família fragilizada tende a tornar-se fonte de suporte ineficaz para a criança enlutada (Domingos \& Maluf, 2003). Estes dados reforçam a importância de um acompanhamento profissional qualificado para auxiliar estas crianças e famílias a lidarem com o impacto emocional que tal vivência acarreta.

\section{Psicoterapia em situação de luto infantil por perda repentina de genitores}

Como ressaltado anteriormente, a perda por morte repentina, tende a ser traumática, principalmente quando esta ocorre na infância. Neste sentido, o atendimento psicológico faz-se de suma importância. Franco (2005) salienta que a pessoa enlutada em condições traumáticas encontra-se fragilizada, geralmente desorganizada, incoerente, assustada e paralisada, necessitando de acolhimento, paciência e atenção. Em função destas peculiaridades, a autora considera que alguns cuidados são primordiais no atendimento psicológico. Entre eles, destaca a importância do psicoterapeuta não ansiar fazer com que a pessoa pare de sofrer rapidamente, pois este seria um mecanismo de tamponamento de sua reação à perda, com graves consequências do ponto de vista psíquico. Considerase importante também não evitar o assunto da perda traumática, assim como não desviar do tema quando o paciente consegue abordá-lo.

Assim, as demandas que surgem em relação ao psicoterapeuta que trabalha com situações de morte repentina e traumática são grandes (Eizirik, Schestatsky, Knijnik, Terra, \& Ceitlin, 2006). Um dos fatores que contribui para isto, além dos aspectos contratransferenciais, é a própria descrença dos pacientes no tra- tamento e na possibilidade de serem ajudados (Eizirik e cols., 2006; Fernandes \& Maia, 2008). Mesmo que as imagens ou memórias do acontecimento mostremse uma presença permanente para o sujeito, essa descrença, somada ao desejo de esquecer o acontecido, pode dificultar o relato do paciente sobre o evento traumático (Fernandes \& Maia, 2008). Muitas vezes o paciente acredita que, evitando pensar, estará também evitando sofrer. No entanto, a inibição dos pensamentos e emoções, segundo os autores, pode exigir muito esforço do indivíduo, provocar ansiedade e ameaçar a saúde. Assim, da mesma forma que a presença da memória é perturbadora, sua supressão ameaça a saúde psíquica, uma vez que dificulta a elaboração da experiência traumática.

Para que haja a elaboração da perda é necessário, portanto, que o indivíduo possa expressar e lidar com os mais diferentes sentimentos suscitados pela morte (Boss, 2005; Knijinik \& Zavaschi, 1994). Contudo, além dos fatores individuais que podem impedir o indivíduo de abordar o trauma, existem fatores sociais para não partilhar algumas experiências adversas, dentre eles a dificuldade das pessoas em ouvir e falar sobre a morte (Fernandes \& Maia, 2008). Assim, pode-se considerar que o luto transcende o âmbito individual, podendo ser considerado um grande desafio não apenas para quem o enfrenta diretamente, mas também para as pessoas que convivem com o indivíduo enlutado, especialmente quando se trata de uma criança.

Tendo em vista o exposto, além da atenção psicológica à criança, em situação de luto infantil por morte de genitores, há necessidade de atendimento também à família, que vive um momento de crise e desorganização. Isto porque, de forma geral, a possibilidade de a criança elaborar o luto encontra-se vinculada ao processo de elaboração do luto pela família e às fantasias inconscientes familiares inerentes a situação vivida (Franco \& Mazorra, 2007).

Boss (2005) salientou que os psicoterapeutas podem ter especial dificuldade de lidar com situações de luto traumático pela impotência que tal vivência desperta, já que não há solução imediata. Em sua experiência no atendimento em grupo aos parentes de vítimas do atentado de 11 de setembro, em Nova Iorque, recontar e ouvir histórias em um ambiente comunitário, familiar e confiável pôde ajudar pais, adolescentes e crianças a reestruturar as suas vidas, apesar da dor 
da perda. Para a autora, o atendimento psicológico pode auxiliar para que a tendência destrutiva de não verbalizar não se desenvolva em casa, evitando o silêncio, que faz a criança sentir-se só e calar-se por medo de tocar em um assunto proibido e de fazer seu pai sobrevivente sofrer. Dentre as intervenções de equipe propostas por Boss (2005), no atendimento aos parentes das vítimas do atentado, as crianças foram incluídas criando-se um espaço para elas brincarem enquanto os adultos conversavam sobre o ocorrido. Além disso, os psicoterapeutas conversavam com as crianças enquanto os pais observavam como falar de forma mais adequada sobre as perdas com seus filhos em casa. Desta forma, abriram espaço para expressão dos sentimentos, favorecendo o processo de luto. Da mesma forma, Eizirik e cols. (2006) consideraram essencial que as vítimas de traumas possam compartilhar suas experiências com os outros, para que, a partir daí restituam um mundo com significado.

Quanto às intervenções em casos de desastres aéreos, Franco (2005) afirmou que deve haver flexibilidade na atuação, mesmo que esta seja pautada em um protocolo. Os desastres diferem de outro tipo de trauma com relação à sua escala de efeitos, o que vai implicar num apoio diferenciado daquele oferecido em situações de perda e estresse. A autora recomendou utilizar a abordagem focal, respeitando o tempo do paciente.

No caso de perda por morte violenta, Affonso (2003) considerou que o atendimento da demanda deve ser imediato. Para o autor, nestas circunstâncias, não haveria dúvida sobre a necessidade de atendimento psicológico. Knijnik e Zavaschi (1994) ressaltaram que, quando há concorrência de inúmeros fatores de risco para um mau prognóstico, pode ser necessário intervir ativamente sobre fatores passíveis de modificação externa. Por exemplo, favorecer a visita ao cemitério, contatar familiares do falecido, orientar as pessoas com quem a criança convive para que criem um ambiente onde ela possa ter lembranças do morto. Reiteraram ainda que os cuidadores da criança também necessitam de auxílio psicológico.

A psicoterapia, para Fernandes e Maia (2008), muitas vezes, constitui-se no primeiro contexto no qual se torna possível para a criança expressar suas emoções mais negativas acerca do trauma vivenciado, enquanto é possível, simultaneamente, ir construindo um novo significado para o evento, buscando a elabo- ração da vivência traumática. Ela é também um potencial catalisador para o desenvolvimento do suporte social, fortalecendo a diminuição dos comportamentos de inibição ou repressão emocional, conduzindo à organização e assimilação da experiência e à melhora da compreensão e a construção de significados: "A psicoterapia eficaz torna-se assim um contexto relacional seguro em que não só são abordados os temas mais difíceis da existência dos pacientes, como é em si própria um espaço de expressão e experienciação do sofrimento" (Fernandes \& Maia, 2008, p. 49).

Assim, do ponto de vista terapêutico, é fundamental para a recuperação do paciente a construção de um ambiente seguro, no qual possa se desenvolver uma confiança mutua, assim como a empatia por parte do psicoterapeuta ao longo de todo o processo (Eizirik e cols., 2006). Ao encontrar um ambiente preparado para recebê-la, a criança enlutada pode sentir-se acolhida, compreendida em um momento de tanta insegurança e desamparo (Franco \& Mazorra, 2007). É na medida em que o paciente percebe o contexto terapêutico como uma situação de segurança e proteção, como o lugar propício para expressar ansiedades e sentimentos de vulnerabilidade, que os afetos vão sendo expressos e o trauma tem a possibilidade de ser entendido (Eizirik e cols., 2006). Ao sentir-se compreendida e aceita, a criança pode expressar com mais tranqüilidade suas fantasias, conflitos e ansiedades, possibilitando a compreensão de seus sentimentos, comportamentos e sintomas (Franco \& Mazorra, 2007). Assim, a aproximação de seu mundo interno caracterizase como importante instrumento para o profissional que trabalha com luto, facilitando a compreensão do trauma, das fantasias e dos conflitos, auxiliando no processo de elaboração da perda (Eizirik e cols., 2006; Franco \& Mazorra, 2007).

\section{CONSIDERAÇÕES FINAIS}

Apesar do número pequeno de publicações no Brasil, os resultados da busca trazem informações relevantes sobre o assunto pesquisado e reforçam a idéia de que desenvolvimentos teóricos na área são de fundamental importância. Cabe ressaltar que, como referido nos artigos revisados, a perda de genitores por morte repentina na infância pode ter inúmeras consequiências a curto, médio e longo prazo. Por isso, a ação profilática, tal como o diálogo aberto da família com a criança, a orientação de profissionais da psico- 
logia em relação a possíveis formas de manejo e, em muitos casos, a psicoterapia são necessários, a fim de minimizar os danos ocasionados por tal evento traumático. $\mathrm{O}$ atendimento psicoterapêutico pode auxiliar a criança e sua família no processo de elaboração da perda, ainda mais em situações em que os adultos cuidadores também se encontram enlutados, apresentando dificuldade de lidar com a situação e com a própria expressão de afetos dolorosos por parte da criança. A expressão das emoções por meio do diálogo ou do brinquedo, em um espaço seguro e acolhedor, como o setting psicoterápico, por mais dolorosa que seja, pode auxiliar a todos os envolvidos a atravessar este momento de vida desorganizador, de forma mais adaptativa.

Cabe salientar que fenômenos contratransferências são intensos neste contexto, pois a perda repentina coloca o ser humano diante da sua própria vulnerabilidade, o que torna o processo de luto ainda mais difícil. Desta forma, o psicólogo necessita estar suficientemente fortalecido para dar suporte emocional à criança enlutada e sua família. Para tanto, é importante que o profissional tenha um profundo conhecimento sobre o tema e sobre si mesmo, procurando diferenciar conflitos inerentes ao atendimento psicológico em situação de luto infantil por perda repentina de genitores, e seus próprios pontos de vulnerabilidade, que podem ser mobilizados diante de tal situação. Desta maneira, não apenas o suporte ao cuidador da criança, mas ao próprio psicoterapeuta, através de sua análise é indicado. Isto porque o psicólogo não necessita apenas estar preparado para lidar com perdas que dizem respeito aos seus pacientes, mas também para lidar com as perdas na sua própria vida.

Como se pode verificar, devido à complexidade do contexto que envolve o luto por perda repentina de genitores na infância, a psicoterapia tem ai um campo de prática com peculiaridades que ainda merecem ser melhor estudadas. Assim sendo, um maior investimento em publicações e pesquisas no Brasil pode auxiliar neste sentido, seja dando maior suporte teórico para os psicoterapeutas, seja orientando instituições e famílias em formas mais adaptativas de lidar com tal situação. Desta forma, se poderia suprir uma lacuna existente em uma área em que a intervenção do psicólogo é necessária e de grande valor profilático, podendo prevenir o desenvolvimento de psicopatologias futuras, envolvendo luto patológico da criança e/ou da família.

\section{REFERÊNCIAS}

Obs.: Referências precedidas de um asterisco indicam estudos incluídos na revisão.

Aberastury, A. (1984). A percepção da morte nas crianças (M. N. Folberg, Trad.). Em A. Aberastury (Org.), A percepção da morte nas crianças e outros escritos (pp.128-139). Porto Alegre: Artes Médicas. (Original publicado em 1978)

*Affonso, R. M. L. (2003). O atendimento psicológico nos casos de luto violento: A construção de um modelo diagnóstico. Psikhê, 8, 31-39.

*Boss, P. (2005). O trauma da perda ambígua: Reflexões ao trabalhar com as famílias de desaparecidos depois de 11/09/2001. Pensando Famílias, 7, 21-44.

Bowlby, J. (1989). Uma base segura: Aplicações clínicas da teoria do apego (V. Dutra, Trad.). São Paulo: Martins Fontes.

Bowlby, J. (1993). Perda, tristeza e depressão. Em J. Bowlby (Org.), Apego e perda: Vol. 3. (L. H. B. Hegenberg \& M. Hegenberg, Trad.). São Paulo: Martins Fontes. (Original publicado em 1973)

Bowlby, J. (2006). Formação e rompimento dos laços afetivos (4 ${ }^{\mathrm{a}}$ ed.) (A. Cabral, Trad.). São Paulo: Martins Fontes. (Original publicado em 1972)

Cole, M., \& Cole, S. R. (2003). Experiências iniciais e vida futura. Em M. Cole, \& S. R. Cole (Orgs.), O desenvolvimento da criança e do adolescente (4⿳亠口冋. . ed.) (M. F. Lopes, Trad.) (pp. 274304). Porto Alegre: Artmed.

*Domingos, B., \& Maluf, M. R. (2003). Experiência de perda e luto em escolares de 13 a 18 anos. Psicologia: Reflexão e Crítica, 16, 577-589.

*Eizirik, M., Schestatsky, S., Knijnik, L., Terra, L., \& Ceitlin, L. H. F. (2006). Contratransferência e trauma psíquico. Revista de Psiquiatria do Rio Grande do Sul, 28, 314-320.

*Fernandes, E., \& Maia, A. C. (2008). Impacto do exercício de psicoterapia nos psicoterapeutas. Análise Psicológica, 1, 47-58.

Ferreira, A. B. H. (1986). Novo dicionário Aurélio da língua portuguesa ( $2^{\mathrm{a}}$ ed.). Rio de Janeiro: Nova Fronteira.

Fonseca, J. P. (2004). Luto antecipatório. Campinas: Livro Pleno.

*Franco, M. H. P. (2005). Atendimento psicológico para emergências em aviação: A teoria revista na prática. Estudos de Psicologia, 10, 177-180.

*Franco, M. H. P., \& Mazorra, L. (2007). Criança e luto: Vivências fantasmáticas diante da morte do genitor. Estudos de Psicologia, 24, 503-511.

Freud, S. (1969). Conferências introdutórias sobre psicanálise. Em J. Salomão (Org.), Edição standard brasileira das obras psicológicas completas de Sigmund Freud (Vol. 15) (J. O. A. Abreu, Trad.). Rio de Janeiro: Imago. (Original publicado em 1916)

Gauderer, C. (1987). A criança, a morte e o luto. Jornal de Pediatria, 62(3), 82, 85-86, 89-90, 93-94.

*Knijnik, J., \& Zavaschi, M. L. S. (1994). Fatores de risco associados à perda parental na infância que dificultam a elaboração do luto. Revista de Psiquiatria do Rio Grande do Sul, 16, 171175.

Laplanche, J., \& Pontalis, J. (1986). Vocabulário de psicanálise (10 ed.) (P. Tamen, Trad.). São Paulo: Martins Fontes. (Original publicado em 1976) 
*Torres, W. C. (1996). A criança diante da morte. Arquivos Brasileiros de Psicologia, 48, 31-42.

*Zavaschi, M. L. S., Satler, F., Poester, D., Vargas, C. F., Piazenski, R., Rohde, L. A. P., \& Eizirik, C. L. (2002). Associação entre trauma por perda na infância e depressão na vida adulta. Revista Brasileira de Psiquiatria, 24, 189-195.

Recebido: $10 / 03 / 2010$ Última revisão: 15/01/2011 Aceite final: 28/02/2011 